\title{
AGE-RELATED FRAILTY: A CLINICAL MODEL FOR GEROSCIENCE?
}

\author{
C. TAKEDA ${ }^{1}$, D. ANGIONI ${ }^{1}$, E. SETPHAN ${ }^{3}$, T. MACARON ${ }^{1}$, P. DE SOUTO BARRETO ${ }^{2}$, S. SOURDET $^{1}$, \\ F. SIERRA ${ }^{2}$, B. VELLAS ${ }^{2}$
}

1. Gérontopôle, Department of Geriatrics, CHU Toulouse, Toulouse, France; 2. Inserm UMR 1027, Toulouse, France; University of Toulouse III, Toulouse, France; Gérontopôle, Department of Geriatrics, CHU Toulouse, Toulouse, France; 3. Saint George's Hospital, Beyrouth, Lebanon. Corresponding author: Dr Catherine Takeda, MD, Gérontopôle, CHU Toulouse, Cité de la Santé, Hôpital La Grave, Place Lange, 31059 Toulouse cedex 9, France, Tel : +33.(0)5.17.77.70.28, Fax +33.(0)5.61.77.70.71, E-mail : takeda.c@chu-toulouse.fr

\begin{abstract}
In their everyday practice, geriatricians are confronted with the fact that older age and multimorbidity are associated to frailty. Indeed, if we take the example of a very old person with no diseases that progressively becomes frail with no other explanation, there is a natural temptation to link frailty to aging. On the other hand, when an old person with a medical history of diabetes, arthritis and congestive heart failure becomes frail there appears an obvious relationship between frailty and comorbidity. The unsolved question is: Considering that frailty is multifactorial and in the majority of cases comorbidity and aging are acting synergistically, can we disentangle the main contributor to the origin of frailty: disease or aging? We believe that it is important to be able to differentiate age-related frailty from frailty related to comorbidity. In fact, with the emergence of geroscience, the physiopathology, diagnosis, prognosis and treatment will probably have to be different in the future.
\end{abstract}

Key words: Frailty causes, aging, age-related frailty, frailty related to diseases, geroscience.

\section{Introduction}

Over the past decades, frailty has commonly been accepted by the scientific and clinical communities $(1,2)$. Frailty is a clinical condition characterized by an excessive vulnerability of the individual to endogenous and exogenous stressors (3). In 2001, Fried et al. (4) established the Frailty phenotype as a clinical syndrome based on the presence of three out of five criteria: unintentional weight loss ( $4.5 \mathrm{~kg}$ in the past year), selfreported exhaustion, weakness (grip strength), slow walking speed and low physical activity. Rockwood and Mitnitski introduced a Frailty Index, which is based on an accumulation of age-related deficits. In their model, frailty is a continuous score summing signs, symptoms, disabilities and diseases (5) (6). The frailty process appears to be a transitional state in the dynamic progression from robustness to disability (7). Many factors leading to frailty have been identified: these include sociodemographic factors (e.g. older age, ethnical background, lower socioeconomic status), physical factors (e.g. obesity, ADL), psychological factors (depressive symptoms) (1), acute events or chronic disease (9).

In everyday clinical practice, we see older people becoming frail without any convincing clinical explanation, especially in the oldest-old. Frailty appears to be related to advancing age, what we can call "age-related frailty". Despite many studies on frailty and its outcomes (10-19), there remains considerable uncertainty as to the cause(s) of frailty $(2,20)$. Because of new insights provided by the emerging field of geroscience, it appears increasingly pertinent to differentiate age-related frailty from frailty related to comorbidity, since the physiopathology, diagnosis, prognosis and treatment will probably be different. In 2003, Fried et al. suggested the terms "primary" and "secondary" frailty to describe respectively frailty in the absence and presence of comorbidities (21).
Fedarko hypothesized that the biology of frailty differed from normal age-related changes and other age-related diseases (22), underlying the importance of distinguishing different clinical Models. Further investigation is needed to validate the origins of frailty from a biological point of view. Geroscience, a new interdisciplinary field that aims to understand the relationship between the biology of aging and the biology of age-related diseases (23), thus has a critical role to play in identifying biomarkers of frailty (24) in order to define the origins of frailty.

The objective of this viewpoint is to underline the importance of distinguishing frailty related to age (25) from frailty related to comorbidity (26).

\section{Age-related frailty}

Among a European population of persons aged over 65 years, $18 \%$ were reported to be frail (95\% CI $15 \%$ to $21 \%$ ) (27). The prevalence of frailty increases with age (4), and this is commonly believed to be related to biological age rather than chronological age (28-31). Hoogendijk proposed frailty as an extreme consequence of the normal aging process (32) according to several longitudinal studies $(33,34)$.

In 2011, Fedarko defines aging as the decline and deterioration of functional properties at the cellular, tissue and organ level (22). Frailty manifests itself as age-related, biological vulnerability to stressors and decreased physiological reserves, resulting in a limited capacity to maintain homeostasis $(35,36)$. According to Fulop et al., frailty is a nonspecific state of vulnerability, which reflects multisystem physiological changes that do not always lead to disease, so some very elderly become frail without a specific life-threatening illness (37). The cellular responses of apoptosis, senescence, repair and the systemic response of immune activation/inflammation Published online October 13, 2020, http://10.1007/s12603-020-1491-4 


\section{THE JOURNAL OF NUTRITION, HEALTH \& AGING}

contribute to aging. In addition, aging reflects how damage propagates through a complex network of interconnected elements (38). These responses, together with changes in homeostatic mechanisms, are likely candidates for pathways that may contribute to the failure seen in frailty (22).

What is still unclear is whether this "age-related frailty" is just the consequence of the aging process in the oldest-old, or rather the consequence of several infra-clinic diseases (e.g. pre-diabetes, elevated blood pressure, limited arthrosis) that progressively lead to frailty. Of course, age-related frailty could be the result of the interactions between these pre-clinical states and the aging process. The main question that remains to be solved is whether it is possible to isolate age alone from the other possible causes of frailty, and thus to propose a model of age-related frailty that could contribute to further discoveries of age-related biomarkers for frailty $(24,39)$. With the aging of the population and the increase in the number of very old persons, the progression to frailty from healthy aging, particularly in the oldest-old (90 years and above), appears to be an important and timely reality. This is confirmed in our clinical practice, particularly in the frailty clinic of the Gérontopole of Toulouse (40). A possible concept for age-related frailty is presented in the study by Angioni et al. (41).

\section{Frailty and chronic disease}

While aging itself is commonly accepted as the main risk factor for chronic diseases (42), new findings suggest the reciprocal may also be true (43). There are well-known links between specific age-related chronic diseases (e.g. diabetes, cancer, CVD) with many hypotheses explaining their associations $(44,45)$.

The relationship between frailty and chronic disease is complex and remains unresolved $(9,26)$. Whether multimorbidity is a precursor of frailty has rarely been studied and the evidence is therefore scarce (26). Although it is agreed that frailty may lead to multimorbidity, it is also widely believed that multimorbidity is a predictor of frailty $(46,47)$ (48). Multimorbidity is defined by the presence of two or more chronic disease $(49,50)$ and tends to arise earlier in life before the onset of frailty (51). Moreover, the associations between frailty and multimorbidity might probably depend on the operational definition of frailty. There are plenty of tools being used for measuring frailty $(4,5,52)$ and multimorbidity (53-55), and these tools are probably not selecting the same profile of individuals. In the context of frailty, the guidelines for the management of multimorbidity are rare (56), with most evidence focusing on single disease management. This poses a great challenge for geriatricians and treating physicians, and increases suspicion towards the role of multimorbidity in the progression of frailty.

In 2018, Hanlon et al. found that frailty was significantly associated with multimorbidity (prevalence 18\% $[4,435 / 25,338])$ in those with four or more long-term conditions
(49). In their findings, multiple sclerosis, chronic fatigue syndrome, connective tissue disease, diabetes and chronic obstructive pulmonary disease were the main diseases associated with frailty. Moreover, comorbidities such as congestive heart failure, myocardial infarction, rheumatoid arthritis, peripheral vascular diseases, diabetes and hypertension have been seen to increase the risk for frailty (37). Vetrano's meta-analysis (26) similarly found that the prevalence of frailty among multimorbid individuals was $16 \%$. Multimorbidity was associated with frailty in pooled analyses (odds ratio $=2.27$ ) Three longitudinal studies suggested a bidirectional association between multimorbidity and frailty $(46,57,58)$.

In conclusion, a single or multiple chronic diseases may trigger the onset of frailty. The geroscience hypothesis is that aging is the major modifiable risk factor for chronic diseases (43). Further studies are needed in order to clarify the relationship between frailty and comorbidity in order to work on aging.

\section{Frailty and Geroscience}

Biological - but not chronological - aging is the major risk factor for age-related diseases, as well as frailty and loss of resilience and function. Recent studies have confirmed that biological aging is malleable and it can be delayed in mammals (42). However, in humans the role of aging on the onset of clinical events has only been studied using chronological age. The field of geroscience aims to determine the mechanisms by which biological aging accelerates morbidity, as a way to identify novel therapeutic targets to maintain function and postpone age-related diseases. The aim is to use the pillars/ hallmarks of aging $(42,59)$ to identify molecular targets that delay the aging process, as a way to delay multiple diseases at once. Examples include the use of senolytics $(42,60)$, inhibitors of nutritional sensing (61), NAD+ precursors (62) and other interventions based on the pillars/hallmarks of aging. Among the different biomarkers of frailty, only inflamaging appears to be a convincing candidate as a biomarker of frailty (63). Application of geroscience principles in the clinic would be strongly abetted by availability of information on the frailty status of the individual, as well as the origin of that frailty, either age-related or disease-driven. It is surmised that geroscience approaches will be most effective in those individuals whose frailty (or pre-frailty) is driven by aging, rather than disease.

While it is currently possible to measure frailty and disease in the clinic, measurements of biological aging are only in their infancy. Several physiology-based approaches are being proposed and tested (64), but molecular measurements of the rate of aging are less well-developed, with the most promising being the epigenetic clocks (64). It is becoming therefore increasingly urgent to identify with further granularity the phenotype of aging and its relation to frailty (65). There is precedent for advancing both science and health care by more 
granular definition of phenotypes. For example, for a longtime in clinical practice, age-related cognitive decline was considered as part of a natural evolution; however, refinements of how we define Alzheimer's disease have led to the identification of prodromal syndromes such as mild cognitive impairment (MCI). We expect that a similar pathway will probably happen for age-related frailty.

\section{Conclusion}

With the increase of very old subjects in our clinical practice, we often observe that these very old subjects $(>90$ years of age) do not present any comorbidity, which probably explains why they live longer than the average. However, at some time, they become frail and we need to understand why. The Inspire program (66-69), is planning to work on the links between biological age and "age-related frailty". Future recommendations for frailty management and prevention will probably have to be adapted to these two etiological pathways, age-related frailty and frailty related to diseases (70), leading to the same clinical condition. We think that aging is in conclusion the main risk factor for frailty (through chronic diseases or not) and consequently aging should be the main target for interventions.

\section{Conflict of interest: The authors have no conflict of interest.}

Ethical standard: The manuscript complies with the Ethical Rules for publication.

Open Access: This article is distributed under the terms of the Creative Commons Attribution 4.0 International License (http://creativecommons.org/licenses/by/4.0/), which permits use, duplication, adaptation, distribution and reproduction in any medium or format, as long as you give appropriate credit to the original author(s) and the source, provide a link to the Creative Commons license and indicate if changes were made.

\section{References}

1. Morley JE, Vellas B, van Kan GA, Anker SD, Bauer JM, Bernabei R, et al. Frailty Consensus: A Call to Action. J Am Med Dir Assoc. juin 2013;14(6):392-7.

2. Bergman H, Ferrucci L, Guralnik J, Hogan DB, Hummel S, Karunananthan S, et al. Frailty: An Emerging Research and Clinical Paradigm--Issues and Controversies. J Gerontol A Biol Sci Med Sci. 1 juill 2007;62(7):731-7.

3. Proietti M, Cesari M. Frailty: What Is It? Adv Exp Med Biol. 2020;1216:1-7.

4. Fried LP, Tangen CM, Walston J, Newman AB, Hirsch C, Gottdiener J, et al. Frailty in Older AdultsEvidence for a Phenotype. J Gerontol Ser A. 1 mars 2001;56(3):M146-57.

5. Mitnitski AB, Mogilner AJ, Rockwood K. Accumulation of deficits as a proxy measure of aging. ScientificWorldJournal. 8 août 2001;1:323-36.

6. Rockwood K, Mitnitski A. Frailty in relation to the accumulation of deficits. J Gerontol A Biol Sci Med Sci. juill 2007;62(7):722-7.

7. Lang P-O, Michel J-P, Zekry D. Frailty syndrome: a transitional state in a dynamic process. Gerontology. 2009;55(5):539-49.

8. Feng Z, Lugtenberg M, Franse C, Fang X, Hu S, Jin C, et al. Risk factors and protective factors associated with incident or increase of frailty among communitydwelling older adults: A systematic review of longitudinal studies. PLoS ONE [Internet]. 15 juin 2017 [cité 16 juin 2020];12(6). Disponible sur: https://www.ncbi. nlm.nih.gov/pmc/articles/PMC5472269/

9. Clegg A, Young J, Iliffe S, Rikkert MO, Rockwood K. Frailty in elderly people. The Lancet. 2 mars 2013;381(9868):752-62.

10. Bersani FS, Canevelli M, Cesari M, Maggioni E, Pasquini M, Wolkowitz OM, et al. Frailty Index as a clinical measure of biological age in psychiatry. J Affect Disord. 1 mai 2020;268:183-7.

11. Searle SD, Mitnitski A, Gahbauer EA, Gill TM, Rockwood K. A standard procedure for creating a frailty index. BMC Geriatr. 30 sept 2008;8:24.

12. Development and validation of a Hospital Frailty Risk Score focusing on older people in acute care settings using electronic hospital records: an observational study [Internet]. [cité 1 avr 2020]. Disponible sur: https://www.ncbi.nlm.nih.gov/pmc/ articles/PMC5946808/

13. Liu H, Shang N, Chhetri JK, Liu L, Guo W, Li P, et al. A Frailty Screening Questionnaire (FSQ) to Rapidly Predict Negative Health Outcomes of Older Adults in Emergency Care Settings. J Nutr Health Aging. 1 juin 2020;24(6):627-33.

14. Ma L, Tang Z, Chan P, Walston JD. Novel Frailty Screening Questionnaire (FSQ) Predicts 8-Year Mortality in Older Adults in China. J Frailty Aging. 1 jany 2019;8(1):33-8.

15. Rivas-Ruiz F, Machón M, Mateo-Abad M, Contreras-Fernández E, Güell C, BaroRodríguez $\mathrm{L}$, et al. Tackling frailty at primary care: evaluation of the effectiveness of a multicomponent intervention through a randomised controlled trial: study protocol. BMJ Open [Internet]. 20 févr 2020 [cité 1 avr 2020];10(2). Disponible sur: https:// www.ncbi.nlm.nih.gov/pmc/articles/PMC7045273/

16. Cesari M, Marzetti E, Thiem U, Pérez-Zepeda MU, Abellan Van Kan G, Landi F, et al. The geriatric management of frailty as paradigm of « The end of the disease era ». Eur J Intern Med. juin 2016;31:11-4.

17. Turner G, Clegg A, British Geriatrics Society, Age UK, Royal College of General Practioners. Best practice guidelines for the management of frailty: a British Geriatrics Society, Age UK and Royal College of General Practitioners report. Age Ageing. nov 2014;43(6):744-7.

18. Landré B, Aegerter P, Zins M, Goldberg M, Ankri J, Herr M. Association Between Hospitalization and Change of Frailty Status in the Gazel Cohort. J Nutr Health Aging. 1 mai 2019;23(5):466-73.

19. Dent E, Martin FC, Bergman H, Woo J, Romero-Ortuno R, Walston JD. Management of frailty: opportunities, challenges, and future directions. The Lancet. 12 oct 2019;394(10206):1376-86.

20. Dent E, Ambagtsheer RC, Beilby J, Stewart S. Frailty and Seasonality. J Nutr Health Aging. 1 juin 2020;24(6):547-9.

21. Fried LP, Walston J. Frailty and failure to thrive. In Hazzard WR, Blass JP, Hlater JB, et al. editors. Principles of Geriatric Medicine and Gerontology. 5. New York: McGraw Hill; 2003. pp. 1487-1502.

22. Fedarko NS. The Biology of Aging and Frailty. Clin Geriatr Med. 1 févr 2011;27(1):27-37.

23. Sierra F, Kohanski R. Geroscience and the trans-NIH Geroscience Interest Group, GSIG. GeroScience. 2017;39(1):1-5.

24. Kane AE, Sinclair DA. Frailty biomarkers in humans and rodents: Current approaches and future advances. Mech Ageing Dev. 1 juin 2019;180:117-28.

25. Mitnitski AB, Mogilner AJ, MacKnight C, Rockwood K. The Accumulation of Deficits with Age and Possible Invariants of Aging. Sci World J. 28 juin 2002;2:1816-22.

26. Vetrano DL, Palmer K, Marengoni A, Marzetti E, Lattanzio F, Roller-Wirnsberger R, et al. Frailty and Multimorbidity: A Systematic Review and Meta-analysis. J Gerontol A Biol Sci Med Sci. 23 2019;74(5):659-66

27. O'Caoimh R, Galluzzo L, Rodríguez-Laso Á, Van der Heyden J, Ranhoff AH, Lamprini-Koula M, et al. Prevalence of frailty at population level in European ADVANTAGE Joint Action Member States: a systematic review and meta-analysis. Ann Ist Super Sanita. sept 2018;54(3):226-38.

28. Jazwinski SM, Kim S. Examination of the Dimensions of Biological Age. Front Genet [Internet]. 26 mars 2019 [cité 1 avr 2020];10. Disponible sur: https://www.ncbi.nlm. nih.gov/pmc/articles/PMC6445152/

29. Wick JY. Understanding frailty in the geriatric population. Consult Pharm J Am Soc Consult Pharm. sept 2011;26(9):634-45.

30. Ferrucci L, Gonzalez-Freire M, Fabbri E, Simonsick E, Tanaka T, Moore Z, et al Measuring biological aging in humans: A quest. Aging Cell. n/a(n/a):e13080.

31. Cesari M, Pérez-Zepeda MU, Marzetti E. Frailty and Multimorbidity: Different Ways of Thinking About Geriatrics. J Am Med Dir Assoc. 1 avr 2017;18(4):361-4.

32. Hoogendijk EO, Afilalo J, Ensrud KE, Kowal P, Onder G, Fried LP. Frailty: implications for clinical practice and public health. Lancet Lond Engl. 12 2019;394(10206):1365-75.

33. Stolz E, Mayerl H, Waxenegger A, Rásky É, Freidl W. Impact of socioeconomic position on frailty trajectories in 10 European countries: evidence from the Survey of Health, Ageing and Retirement in Europe (2004-2013). J Epidemiol Community Health. 2017:71(1):73-80

34. Hoogendijk EO, Rockwood K, Theou O, Armstrong JJ, Onwuteaka-Philipsen BD, Deeg DJH, et al. Tracking changes in frailty throughout later life: results from a 17-year longitudinal study in the Netherlands. Age Ageing. 01 2018;47(5):727-33.

35. Fried LP, Ferrucci L, Darer J, Williamson JD, Anderson G. Untangling the Concepts of Disability, Frailty, and Comorbidity: Implications for Improved Targeting and Care. J Gerontol Ser A. 1 mars 2004;59(3):M255-63.

36. Walston J, McBurnie MA, Newman A, Tracy RP, Kop WJ, Hirsch CH, et al. Frailty and Activation of the Inflammation and Coagulation Systems With and Withou 


\section{THE JOURNAL OF NUTRITION, HEALTH \& AGING}

Clinical Comorbidities: Results From the Cardiovascular Health Study. Arch Intern Med. 11 nov 2002;162(20):2333-41.

37. Fulop T, Larbi A, Witkowski JM, McElhaney J, Loeb M, Mitnitski A, et al. Aging, frailty and age-related diseases. Biogerontology. 1 oct 2010;11(5):547-63.

38. Mitnitski AB, Rutenberg AD, Farrell S, Rockwood K. Aging, frailty and complex networks. Biogerontology. 1 août 2017;18(4):433-46.

39. Cardoso AL, Fernandes A, Aguilar-Pimentel JA, de Angelis MH, Guedes JR, Brito MA, et al. Towards frailty biomarkers: Candidates from genes and pathways regulated in aging and age-related diseases. Ageing Res Rev. 1 nov 2018;47:214-77.

40. Tavassoli N, Guyonnet S, Abellan Van Kan G, Sourdet S, Krams T, Soto M-E, et al. Description of 1,108 older patients referred by their physician to the "Geriatric Frailty Clinic (G.F.C) for assessment of frailty and prevention of disability" at the gerontopole. J Nutr Health Aging. 1 mai 2014;18(5):457-64

41. Angioni D, Macaron T, Takeda C, Sourdet S, Cesari M, Virecoulon Giudici K et al. Can we distinguish age-related frailty from frailty related to diseases? Data from the MAPT Study. Submitted to JNHA, 2020

42. Kennedy BK, Berger SL, Brunet A, Campisi J, Cuervo AM, Epel ES, et al. Geroscience: Linking Aging to Chronic Disease. Cell. 6 nov 2014;159(4):709-13.

43. Hodes RJ, Sierra F, Austad SN, Epel E, Neigh GN, Erlandson KM, et al. Disease drivers of aging. Ann N Y Acad Sci. déc 2016;1386(1):45-68.

44. Marengoni A, Angleman S, Melis R, Mangialasche F, Karp A, Garmen A, et al. Aging with multimorbidity: a systematic review of the literature. Ageing Res Rev. sept 2011;10(4):430-9.

45. Marengoni A, Zucchelli A, Vetrano DL, Aloisi G, Brandi V, Ciutan M, et al. Heart failure, frailty, and pre-frailty: A systematic review and meta-analysis of observational studies. Int J Cardiol. 19 avr 2020;

46. Theou O, Rockwood MRH, Mitnitski A, Rockwood K. Disability and co-morbidity in relation to frailty: how much do they overlap? Arch Gerontol Geriatr. oct 2012;55(2):e1-8.

47. Rockwood K, Andrew M, Mitnitski A. A comparison of two approaches to measuring frailty in elderly people. J Gerontol A Biol Sci Med Sci. juill 2007;62(7):738-43

48. Bergman H, Ferrucci L, Guralnik J, Hogan DB, Hummel S, Karunananthan S, et al Frailty: An Emerging Research and Clinical Paradigm - Issues and Controversies. J Gerontol A Biol Sci Med Sci. juill 2007;62(7):731-7.

49. Hanlon P, Nicholl BI, Jani BD, Lee D, McQueenie R, Mair FS. Frailty and pre-frailty in middle-aged and older adults and its association with multimorbidity and mortality: a prospective analysis of 493737 UK Biobank participants. Lancet Public Health. 14 juin 2018;3(7):e323-32.

50. Calderón-Larrañaga A, Vetrano DL, Onder G, Gimeno-Feliu LA, CoscollarSantaliestra C, Carfí A, et al. Assessing and Measuring Chronic Multimorbidity in the Older Population: A Proposal for Its Operationalization. J Gerontol Ser A. 1 oct 2017;72(10):1417-23

51. Mitnitski A, Rockwood K. The rate of aging: the rate of deficit accumulation does not change over the adult life span. Biogerontology. févr 2016;17(1):199-204.

52. Rolfson DB, Majumdar SR, Tsuyuki RT, Tahir A, Rockwood K. Validity and reliability of the Edmonton Frail Scale. Age Ageing. 1 sept 2006;35(5):526-9.

53. Prados-Torres A, Calderón-Larrañaga A, Hancco-Saavedra J, Poblador-Plou B, van den Akker M. Multimorbidity patterns: a systematic review. J Clin Epidemiol. 1 mars 2014;67(3):254-66.

54. Charlson ME, Charlson RE, Peterson JC, Marinopoulos SS, Briggs WM, Hollenberg JP. The Charlson comorbidity index is adapted to predict costs of chronic disease in primary care patients. J Clin Epidemiol. 1 déc 2008;61(12):1234-40.

55. Beloosesky Y, Weiss A, Mansur N. Validity of the Medication-Based Disease Burden Index Compared with the Charlson Comorbidity Index and the Cumulative Illness Rating Scale for Geriatrics. Drugs Aging. 1 déc 2011;28(12):1007-14.
56. Overview | Multimorbidity: clinical assessment and management I Guidance I NICE [Internet]. NICE; [cité 16 juin 2020]. Disponible sur: https://www.nice.org.uk/ guidance/ng56

57. Castell M-V, Sánchez M, Julián R, Queipo R, Martín S, Otero Á. Frailty prevalence and slow walking speed in persons age 65 and older: implications for primary care. BMC Fam Pract. 19 juin 2013;14(1):86.

58. Hee-Won Jung, Il-Young Jang, Young Soo Lee, Chang Ki Lee, Eun-Il Cho, Woo Young Kang et al. Prevalence of Frailty and Aging-Related Health Conditions in Older Koreans in Rural Communities: a Cross-Sectional Analysis of the Aging Study of Pyeongchang Rural Area: JKMS : Journal of Korean Medical Science [Internet]. [cited 22 juill 2020]. Available: https://jkms.org/DOIx.php?id=10.3346/jkms.2016.31.3.345 Feb 04, 2016. https://doi.org/10.3346/jkms.2016.31.3.345

59. López-Otín C, Blasco MA, Partridge L, Serrano M, Kroemer G. The Hallmarks of Aging. Cell. 6 juin 2013;153(6):1194-217

60. Guerville F, De Souto Barreto P, Ader I, Andrieu S, Casteilla L, Dray C, et al. Revisiting the Hallmarks of Aging to Identify Markers of Biological Age. J Prev Alzheimers Dis. 1 janv 2020;7(1):56-64.

61. Kaeberlein M. Translational geroscience: A new paradigm for 21 st century medicine. Transl Med Aging. 1 oct 2017;1:1-4.

62. Bonkowski MS, Sinclair DA. Slowing ageing by design: the rise of NAD + and sirtuin-activating compounds. Nat Rev Mol Cell Biol. nov 2016;17(11):679-90.

63. Zampino M. Biomarkers in the path from cellular senescence to frailty. Exp Gerontol 2020;7.

64. Belsky DW, Moffitt TE, Cohen AA, Corcoran DL, Levine ME, Prinz JA, et al. Eleven Telomere, Epigenetic Clock, and Biomarker-Composite Quantifications of Biological Aging: Do They Measure the Same Thing? Am J Epidemiol. 1 juin 2018;187(6):1220-30.

65. Guralnik J, Bandeen-Roche K, Bhasin SAR, Eremenco S, Landi F, Muscedere J, et al Clinically Meaningful Change for Physical Performance: Perspectives of the ICFSR Task Force. J Frailty Aging. 1 janv 2020;9(1):9-13.

66. De Souto Barreto P, Guyonnet S, Ader I, Andrieu S, Casteilla L, Davezac N, et al. The inspire research initiative: a program for geroscience and healthy aging research going from animal models to humans and the healthcare system. J Frailty Aging [Internet]. 1 mars 2019 [cité 8 mai 2020]; DOI: 10.14283/jfa.2020.18 1

67. Guyonnet S, Rolland Y, Takeda C, Ousset P-J, Ader I, Davezac N, et al. The INSPIRE Bio-Resource Research Platform for Healthy Aging and Geroscience: Focus on the Human Translational Research Cohort (The INSPIRE-T Cohort). J Frailty Aging [Internet]. 10 juill 2020 [cité 21 juill 2020]; DOI: 10.14283/jfa.2020.38

68. N. Tavassoli, A. Piau, C. Berbon, J. De Kerimel, C. Lafont, P. De Souto Barreto, et al Framework Implementation of the INSPIRE ICOPE-CARE program in collaboration with the World Health Organization (WHO) in the Occitania region. 2020 [cité 21 juill 2020]; DOI: $10.14283 /$ jfa.2020.26

69. Santin Y, Lopez S, Ader I, Andrieu S, Blanchard N, Carrière A, et al. Towards a Large-Scale Assessment of the Relationship Between Biological and Chronological Aging: The Inspire Mouse Cohort. J Frailty Aging [Internet]. 7 août 2020 [cité 6 sept 2020]; Disponible sur: https://doi.org/10.14283/jfa.2020.43

70. Dent E, Morley JE, Cruz-Jentoft AJ, Woodhouse L, Rodríguez-Mañas L, Fried LP, et al. Physical Frailty: ICFSR International Clinical Practice Guidelines for Identification and Management. J Nutr Health Aging. 2019;23(9):771-87. 